\title{
TGA/VSD/LVOTO: Evolution of surgical therapy
}

\author{
Ralph S. Mosca, MD
}

See related article on pages 1349-55.

The surgical treatment of transposition of the great arteries, ventricular septal defect (VSD), and significant left ventricular outflow tract (LVOT) obstruction continues to evolve. Initial atrial switch procedures, combined with VSD closure and LVOT resection, with our without a conduit, proved unsatisfactory in the long term and have been largely abandoned. ${ }^{1}$ The Rastelli procedure preserved the left ventricle as the systemic ventricle, and with technical refinements the early and midterm results continue to improve. ${ }^{2}$ The long, circuitous LVOT, the circumference of which is bounded by muscle and prosthetic material, has resulted in significant rates of LVOT obstruction and reintervention. This, along with mandatory right ventricle (RV) to pulmonary artery (PA) conduit changes and the persistent threat of dysrhythmias, has led to suboptimal longer term survival. ${ }^{3}$ Attempts to deal with the biventricular outflow tract issues inherent in this lesion led to the introduction of and rise in popularity of the Nikaidoh-Bex and reparation letage ventriuculaire procedures. ${ }^{4,5}$ Both of these provide a more anatomic LVOT and hold the promise of fewer future interventions. Both can prove to be more technically challenging, however, and carry the risk of early coronary ischemia, PA distortion, and perhaps late aortic insufficiency.

The current study in this issue of the Journal by Raju and colleagues $^{6}$ is an update on their experience treating patients with dextrotransposition of the great arteries, VSD, and pulmonary stenosis. It is one of the largest single-center series to date, consisting of 32 patients operated on during a 15 -year period. Three patients $(9.3 \%)$ required early reoperation, reflecting the complexity of these procedures, and 14 patients $(45.2 \%)$ needed a reintervention during follow-up, mainly for RV-PA conduit dilation. Six patients $(19 \%)$ underwent surgical reoperation,

From the Department of Cardiothoracic Surgery, NYU Langone Medical Center, New York, NY.

Disclosures: Author has nothing to disclose with regard to commercial support.

Received for publication Jan 3, 2015; accepted for publication Jan 7, 2015; available ahead of print Feb 19, 2015.

Address for reprints: Ralph S. Mosca, MD, NYU Langone Medical Center, Suite 9V,

530 First Ave, New York, NY 10016 (E-mail: Ralph.Mosca@nyumc.org).

J Thorac Cardiovasc Surg 2015;149:1356-7

$0022-5223 / \$ 36.00$

Copyright (c) 2015 by The American Association for Thoracic Surgery

http://dx.doi.org/10.1016/j.jtcvs.2015.01.008 all for replacement of RV-PA conduits. Of note, 2 patients had moderate aortic insufficiency at latest follow-up, an ongoing concern with this procedure. ${ }^{7}$

As with any newly adopted technique, it is the subtleties of the procedure that are paramount to good results and often are borne out with time. The conclusions of this study

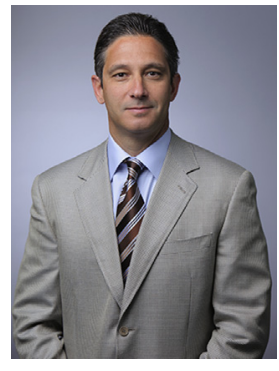
point to excellent survival and confirm the durability of the LVOT reconstruction. Both the use of the RV-PA conduit and a transannular patch resulted in good early outcomes, with a trend toward fewer reoperations in the transannular patch cohort. Perhaps more important are the experiential pearls and flexibility in technique that can be gleaned from the series. It has become clear that the potential pitfalls of the aortic translocation procedure center around harvesting the aortic root, potential coronary obstruction during root translocation, and methods to avoid significant RV outflow tract obstruction. Raju and colleagues ${ }^{6}$ describe their thought processes in this regard; the advantages of aortic harvesting, with or without a crossclamped aorta, sufficient epicardial coronary mobilization, and preservation of the neoaortic sinotubular junction, as well as circumstances in which the aorta can be translocated with intact coronaries or when partial reimplantation or full implantation is required (eg, left circumflex from the right coronary artery or inverted coronary arteries). The use of the LeCompte maneuver and selective use of RV-PA conduits in younger children, or transannular patches in older children, helped to reduce the need for RV outflow tract interventions.

The combination of dextrotransposition of the great arteries, double-outlet RV with pulmonary stenosis, and VSD encompasses a wide spectrum of anatomic relationships and physiologic presentations. The ventricular size and function; great vessel dimensions and spatial relationships; size and location of the VSD; the presence, severity, and constitution of LVOT obstruction; atrioventricular valve structural abnormalities; and coronary anatomy all must be understood and considered. It is the nuances of each circumstance that will guide the optimal choice of intervention. The focus of recent articles has been the categorization and definition of the best procedure for each particular patient. ${ }^{8}$ The limitations of this study-its retrospective, single-center, nonprotocol design with a relatively small number of patients and a median follow-up of only 2 years - may limit our ability to be definitive regarding the long-term benefits of either the method of RV-PA 
reconstruction or the ultimate fate of the aortic valve. From the experience of Raju and colleagues, ${ }^{6}$ however, we can better understand the intricacies of the aortic translocation procedure and in the process help to choose the best procedures for our patients.

\section{References}

1. Daicoff GR, Schiegler GL, Elliot LP, Van Mierop LH, Bartley TD, Gessner IH, et al. Surgical repair of transposition of the great arteries with pulmonary stenosis. Ann Thorac Surg. 1969;7:529-38.

2. Brown JW, Ruzmetov M, Huynh D, Rodefeld MD, Turrentine MW, Fiore AC. Rastelli operation for transposition of the great arteries with ventricular septal defect and pulmonary stenosis. Ann Thorac Surg. 2011;91:188-93; discussion 193-4.

3. Dearani JA, Danielson GK, Puga FJ, Mair DD, Schleck CD. Late results of the Rastelli operation for transposition of the great arteries. Semin Thorac Cardiovasc Surg Pediatr Card Surg Annu. 2001;4:3-15.
4. Nikaidoh $\mathrm{H}$. Aortic translocation and biventricular outflow tract reconstruction A new surgical repair of transposition of the great arteries associated with ventricular septal defect and pulmonary stenosis. J Thorac Cardiovasc Surg. 1984;88:365-72.

5. Lecompte Y, Neveux JY, Leca F, Zannini L, Tu TV, Duboys Y, et al. Reconstruction of the pulmonary outflow tract without a prosthetic conduit. J Thorac Cardiovasc Surg. 1982;82:727-33.

6. Raju V, Myers PO, Quinonez LG, Emani SM, Mayer JE Jr, Pigula FA, et al. Aortic root translocation (Nikaidoh procedure): Intermediate follow-up and impact of conduit type. J Thorac Cardiovasc Surg. 2015;149:1349-55.

7. Morell VO, Jacobs JP, Quintessenza JA. Aortic translocation in the management of transposition of the great arteries with ventricular septal defect and pulmonary stenosis: results and follow-up. Ann Thorac Surg. 2005;79:2089-92; discussion 2092-3.

8. Honjo O, Yasuhiro Y, Bharucha T, Mertens L, Caldarone CA, Redington AN, et al Anatomical factors determining surgical decision making in patients with transposition of the great arteries with left ventricular outflow tract obstruction. Eur J Cardiothorac Surg. 2013;44:1085-94; discussion 1094. 